$\xi=$ 줄

\title{
Flood modelling using satellite-based precipitation estimates and digital elevation model in eastern Iraq
}

\author{
Zaidoon T. Abdulrazzaq *, Nadia A. Aziz, Abdulkareem A. Mohammed \\ Directorate of Space and Communications, Ministry of Science and Technology, Baghdad, Iraq \\ *Corresponding author E-mail: zaidoon.taha@live.com
}

\begin{abstract}
Increasingly available and a virtually uninterrupted supply of satellite-estimated rainfall data is gradually becoming a cost-effective source of input for flood prediction under a variety of circumstances. The study conducted in Wasit province/Eastern Iraq when a flood occurs due to heavy rainfall in May 2013. In this study the capability of Tropical Rainfall Measuring Mission (TRMM) rainfall daily data have been used to estimate the relationship between measured precipitation and the Digital Elevation Model (DEM), also to study the relationship between rainfall intensity and flood waters areas. Rainfall estimation by remote sensing using satellite-derived data from the Tropical Rainfall Measuring Mission (TRMM) is a possible means of supplementing rain gauge data, having the better spatial cover of rainfall fields. The approach used throughout this paper has integrated recently compiled data derived from satellite imagery (rainfall, and digital elevation model) into a GIS geodatabase to study the relationship between rainfall intensity and floodwater's areas then the results' comparison with the Normalized Difference Water Index (NDWI) after the flood. ArcGIS software has been used to process, analyze the archived Tropical Rainfall Measuring Mission (TRMM) precipitation data, and calculate NDWI from Landsat 8 images. In conclusions, the study explains the flood-area clearly captured by the TRMM measurements; and the region's water increased. Also, good correlation between measured precipitation and the Digital Elevation Model (DEM) has been detected.
\end{abstract}

Keywords: TRMM; DEM; Zonal; Rainfall; Remote Sensing; Flood; NDWI.

\section{Introduction}

Floods influence more people globally than any other types of natural disaster, and they usually return every year in flood-prone regions. Local dry/wet conditions are of great concern in regional water resource and floods/droughts disaster risk management. Due to climatic variability, floods have been increased recently in several regions around the world. The resulting impact from floods is often harmful.

Iraq, the country that is known as a country with dry climatic conditions suffered from heavy rainfall early May 2013, which comes after a significant period of drought, especially in southern cities of Iraq. Rain's flood affected Wasit, Dhi Qar and Maysan provinces of Iraq. The huge rainfall within short spring period and it became a natural hazard. Infrastructure, crops and housing have been destroyed. Satellite-based precipitation products have greatly improved their accuracy and applicability and are expected to offer an alternative to grind rain gauges data. In addition, consider helpful tools for monitoring precipitation over regions with varied meteorological conditions and gives the status of land cover.

A common challenge in modeling watershed hydrology is obtaining accurate weather input data, often one of the most important drivers for watershed models. Obtaining representative meteorological data in an area can be complex. The data consisting of precipitation, temperature, and other relevant weather information. So that the Rainfall estimation by remote sensing using satellitederived data may be a possible alternative to supplementing rain gauge data, having the better spatial cover of rainfall fields. Hence, working with spatial rainfall data can be a better source than the data obtained from point measurements (Wang et al.
2009). However, according to Nicholson et al. (2003), neither rain gauges nor satellite-based estimates are perfect indicators of rainfall. The water of the rainfall is partially lost through evaporation, and the rest infiltrates into the shallow soil where it may subsequently be either lost by evaporation or utilized by some native vegetation. After rather heavy rains, Runoff is possible a considerable amount of water may percolate to deeper soil layers.

The Tropical Rainfall Measuring Mission (TRMM) is a joint between NASA and the Japanese space agency (JAXA). satellite mission to provide the first detailed and comprehensive data set of the four-dimensional distribution of rainfall and latent heating over vastly under sampled tropical and subtropical oceans and continents $\left(40^{\circ} \mathrm{S}-40^{\circ} \mathrm{N}\right)$ (Kummerow et al. 1998). Despite the fact that satellite rainfall products spatial scales are ranging from $0.25^{\circ}$ to $5^{\circ}$ and assumed to be coarse for hydrologic modeling, they are used in wide range of applications due to being cost-effective and easy availability (Harris et al. 2007). As its name implies, TRMM was originally conceived mainly for the study of tropical rainfall. Over the years, however, TRMM has proven to be an invaluable resource in other application areas, such as flood and drought monitoring.

In interdisciplinary research and applications, the use with the TRMM data is frequently observed. For instance; to monitor heavy rains (Minghu et al. 2008), to study historical events like El Nino (Adler et al. 2000), to study tropical infection disease (Liu et al. 2002), to determine land surface wetness (Gu et al. 2002) and to estimate crop yield (Chiu et al. 2004), TRMM data products are used. The objective of this study has been to integrate recently compiled data derived from satellite imagery (rainfall, and digital elevation model) into a GIS geodatabase to study the relationship 
between rainfall intensity and floodwater's areas, then comparison the results with NDWI after the flood.

\section{Location of the study area}

As shown in Figure 1, the research is carried out in Wasit province eastern of Iraq. It occupies an area of about $\mathrm{km}^{2}$. The study area located between latitudes $\left(31^{\circ} 30^{\prime}-33^{\circ} 30^{\prime} \mathrm{N}\right)$ and longitudes $\left(44^{\circ}\right.$ $30^{\prime}-47^{\circ} 00^{\prime} \mathrm{E}$ ), with the elevation of the area varies from 9-940 $\mathrm{m}$, above sea level and the general slope of land decreases from Northeast to Southwest and from eastern borders toward the centre (Fig.1).

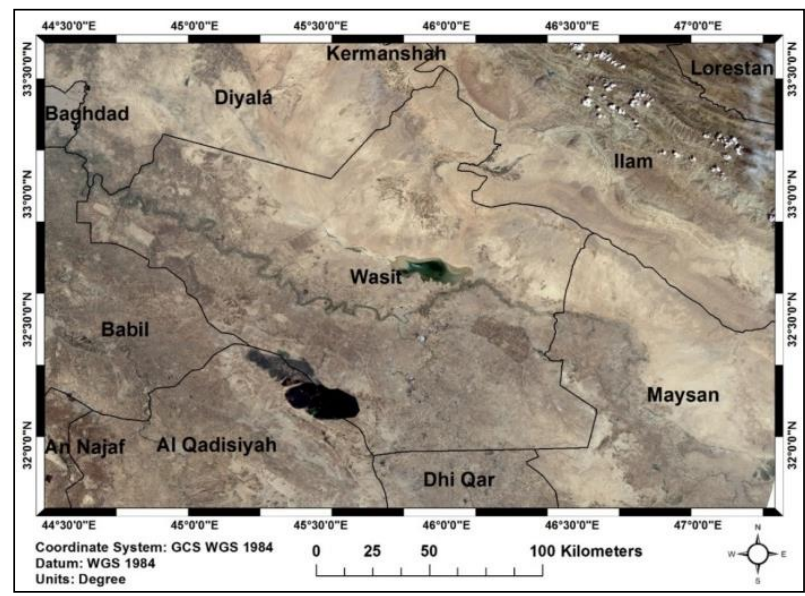

Fig. 1: Location of the Study Area.

\section{Data and methodology}

Among advanced data collection technologies, the satellite has emerged as an effective tool for monitoring and assessment remote areas. In this study, satellite images, DEM and climate data then these layers analyzed in GIS system. The hydrological analysis was performed using DEM and hydrology tools. ArcGIS version 10.5 used to analyses the Landsat 8 image, DEM and Rainfall data (Table 1).

Table 1: The Dataset Details

\begin{tabular}{|c|c|c|}
\hline Data & Resolution & Details \\
\hline Satellite Image & $30 \mathrm{~m}$ & Landsat 8 \\
\hline DEM & $1 \operatorname{ArcSec}(30 \mathrm{~m})$ & STRM \\
\hline Rainfall & $0.25^{\circ} \times 0.25^{\circ}$ & TRMM \\
\hline
\end{tabular}

\subsection{Digital elevation model (DEM)}

Topography plays a crucial role in many ecosystem and hydrological processes. The movement of water within the surface (or nearsurface) runoff and interflow are driven by topography which thereafter plays an important role in concentrating water flows that eventually generate. DEM of the study area (Fig. 2) was extracted from the SRTM data using Arc GIS V.10.3 software. DEM was employed to offer varieties data that assist in producing the slop map (Fig.3), landforms map of the studied areas in order to investigate the spatial relationship rainfall intensity, and flood waters areas using the zonal tool.
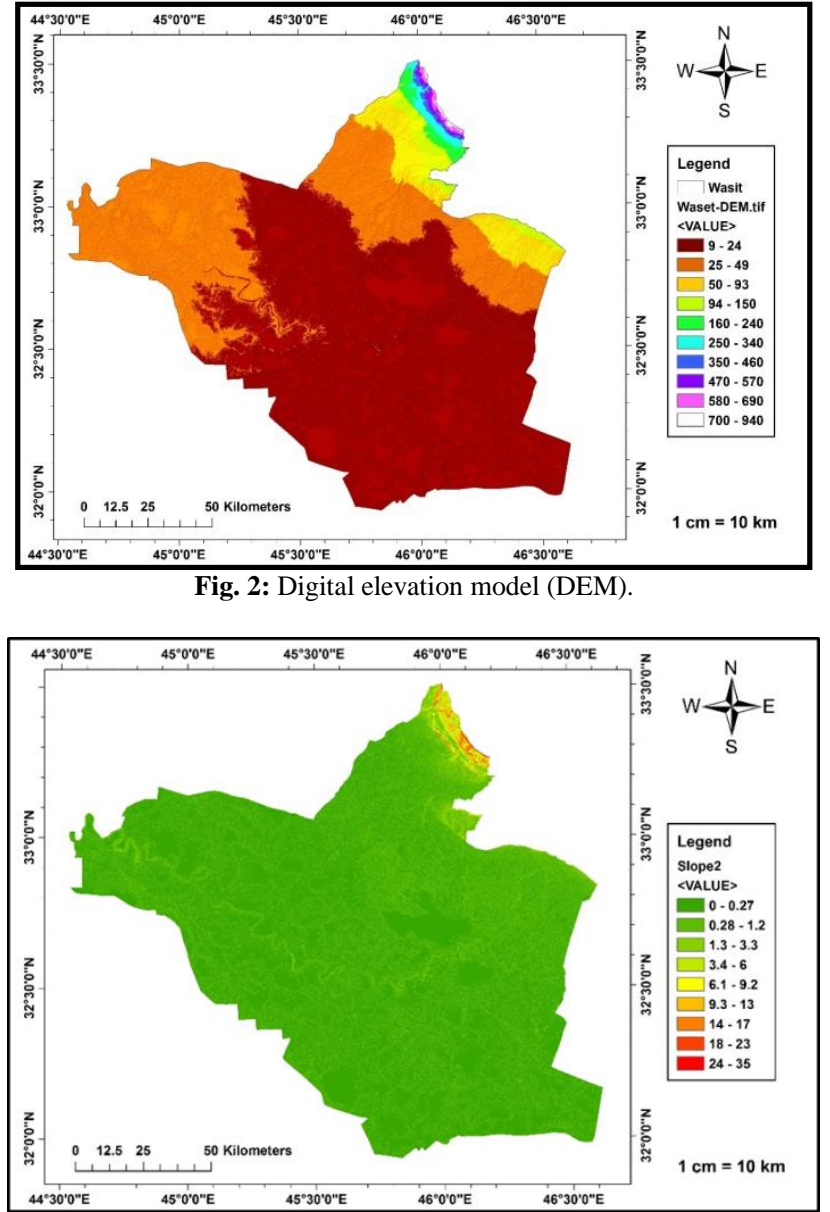

Fig. 3: Slope Map per Degree.

\subsection{Satellite-based precipitation data: TRMM}

For satellite rainfall data, TRMM Multi-Satellite Precipitation Analysis (TMPA) product have been used in this study, with a spatial resolution of $0.25^{\circ} \times 0.25^{\circ}$. The TMPA provides a calibration-based sequential scheme for combining rainfall estimates from various satellites, at fine scales (Huffman et al. 2007).

TRMM product 3B42 (daily temporal resolution) were gathered through TOVAS system (NASA, 2010). To download data from TOVAS, first, the area of interest is defined, and then with the selection of time interval, data are visualized. There are four format types to download data, HDF, NetCDF, ASCII, and Google Earth KMZ. In this study, results are downloaded using NetCDF format to operate in ArcGIS. The NASA TRMM team develops tools and methods for combining and analyzing precipitation data from both terrestrial and space-based sources and publishes highquality data products resulting from this work. The four days (From 4-8 May) accumulated rainfall map is shown in figure 4.

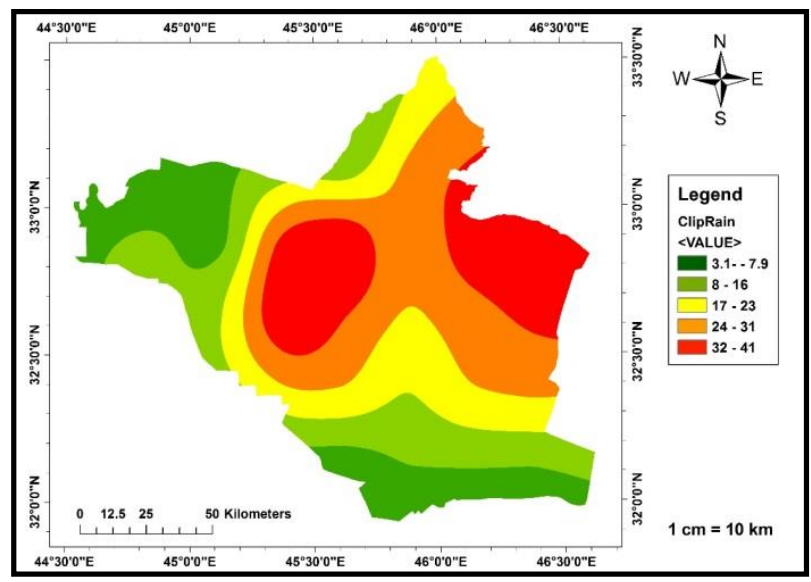

Fig. 4: The Accumulated Rainfall for 4 Days. 


\subsection{McIDAS-V software package}

McIDAS-V is a free open source, visualization and data analysis software package that is the next generation in SSEC's 40-year history of sophisticated McIDAS software packages. McIDAS-V displays weather satellite (including hyper spectral).). McIDAS-V can also analyze and manipulate the data with its powerful mathematical functions. McIDAS-V software package has been used within this study to monitoring the clouds' movement and density that led to heavy rain in Wasit city/Eastern Iraq in May 2013. The heavy rain starts on 4 to 8 May (Fig.5).

\section{GIS hydrological modelling}

The hydrological modeling is done using topographical information (DEM). The procedure of hydrologic analysis using Arc GIS illustrates in figure 6. Firstly, the flow direction analyzed the current direction grid from which the direction where each mesh flowed out was requested from DEM that removed the hollow; this was made by using Flow Direction. In addition, Flow Accumulation was used to create the accumulation flowing quantity grid from which the number of meshes (accumulation flowing quantity) flowed from the current direction grid into each mesh. The accumulation flowing quantity of the river was analyzed from the accumulation flowing quantity grid. Figure 7 shows the results watershed delineation map.

A "zone" is all the areas/cells with the same value. Using the Zonal Statistics tool, it could be Calculate a statistic within the zones for each cell in a raster. After input the slope raster zones. The output may be as a raster, summary table, or chart which include max. Flow length per watershed, Average slope per watershed and Average curve number per watershed. Figure 8 illustrates the thematic zonal Statistics layers used in this study.

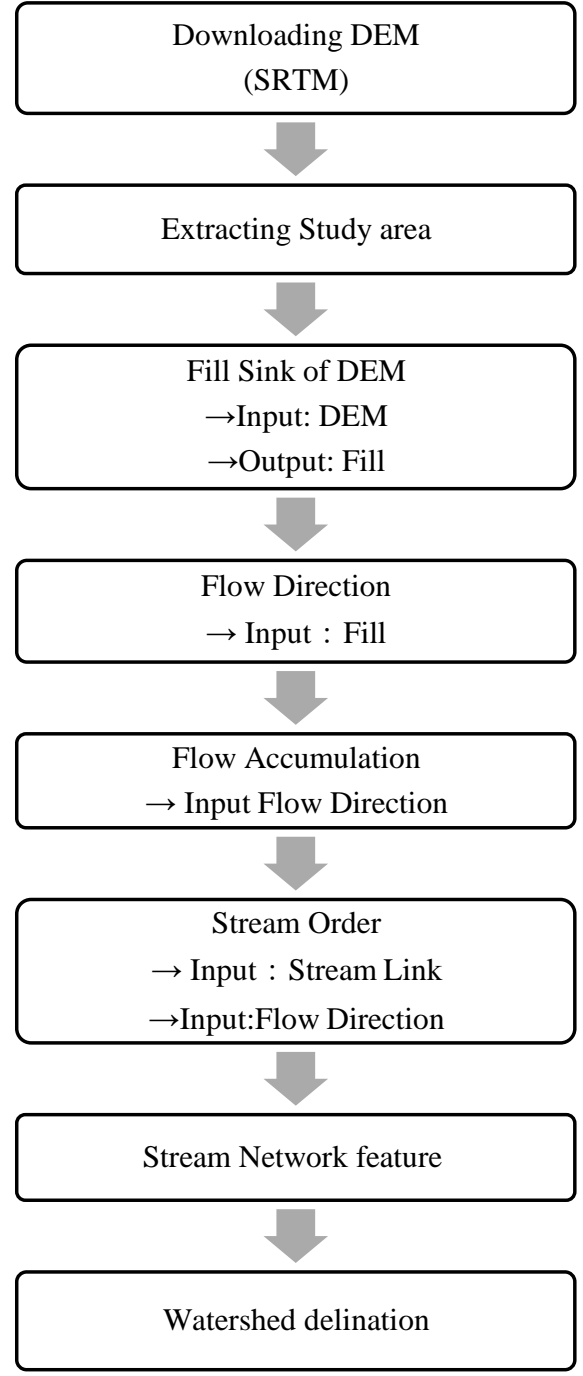

Fig. 6: Hydrologic Analysis using ArcGIS/ Hydrology Tools Flowchart.

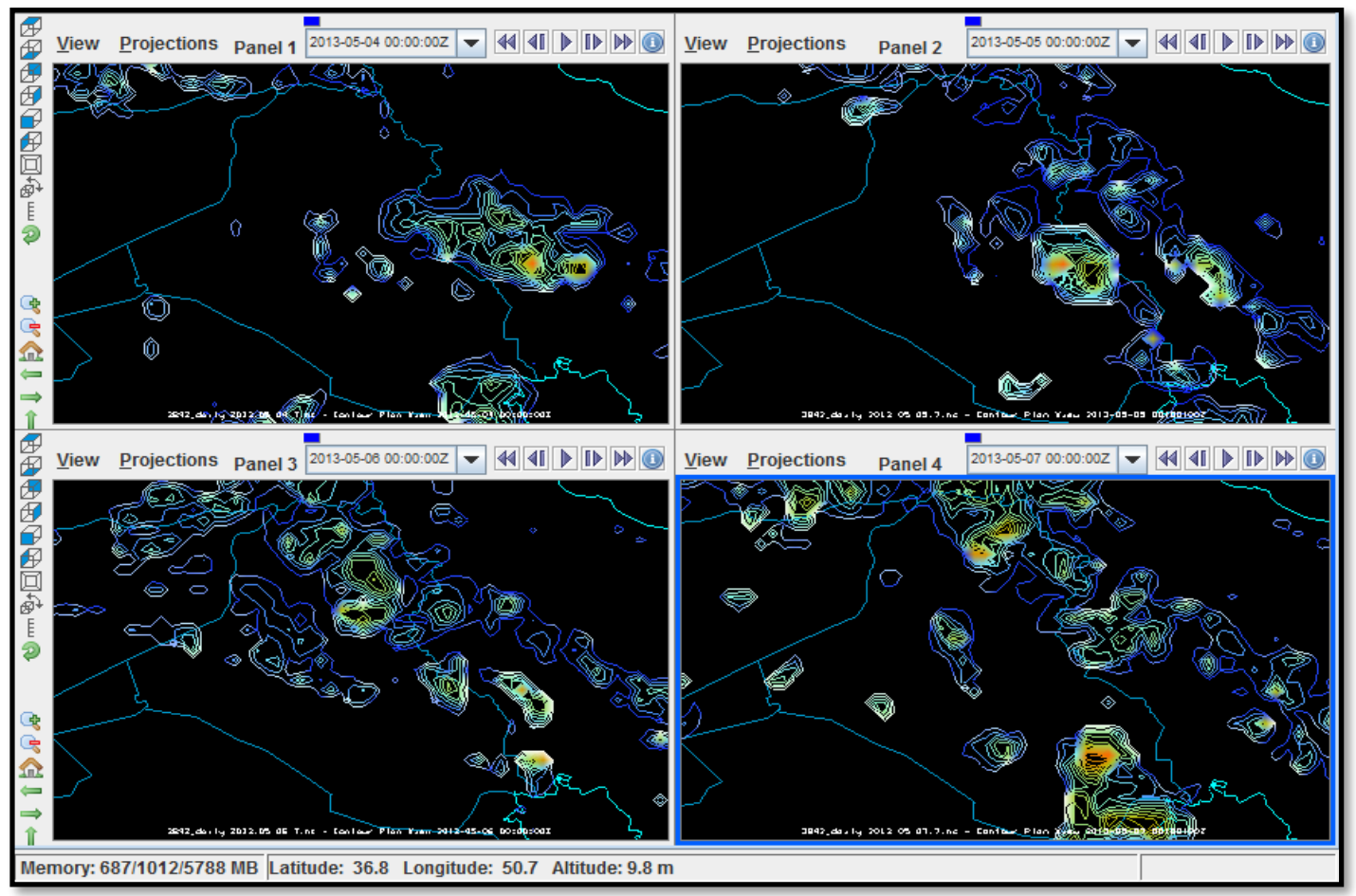

Fig. 5: Rainstorm Monitoring by McIDAS-V. 

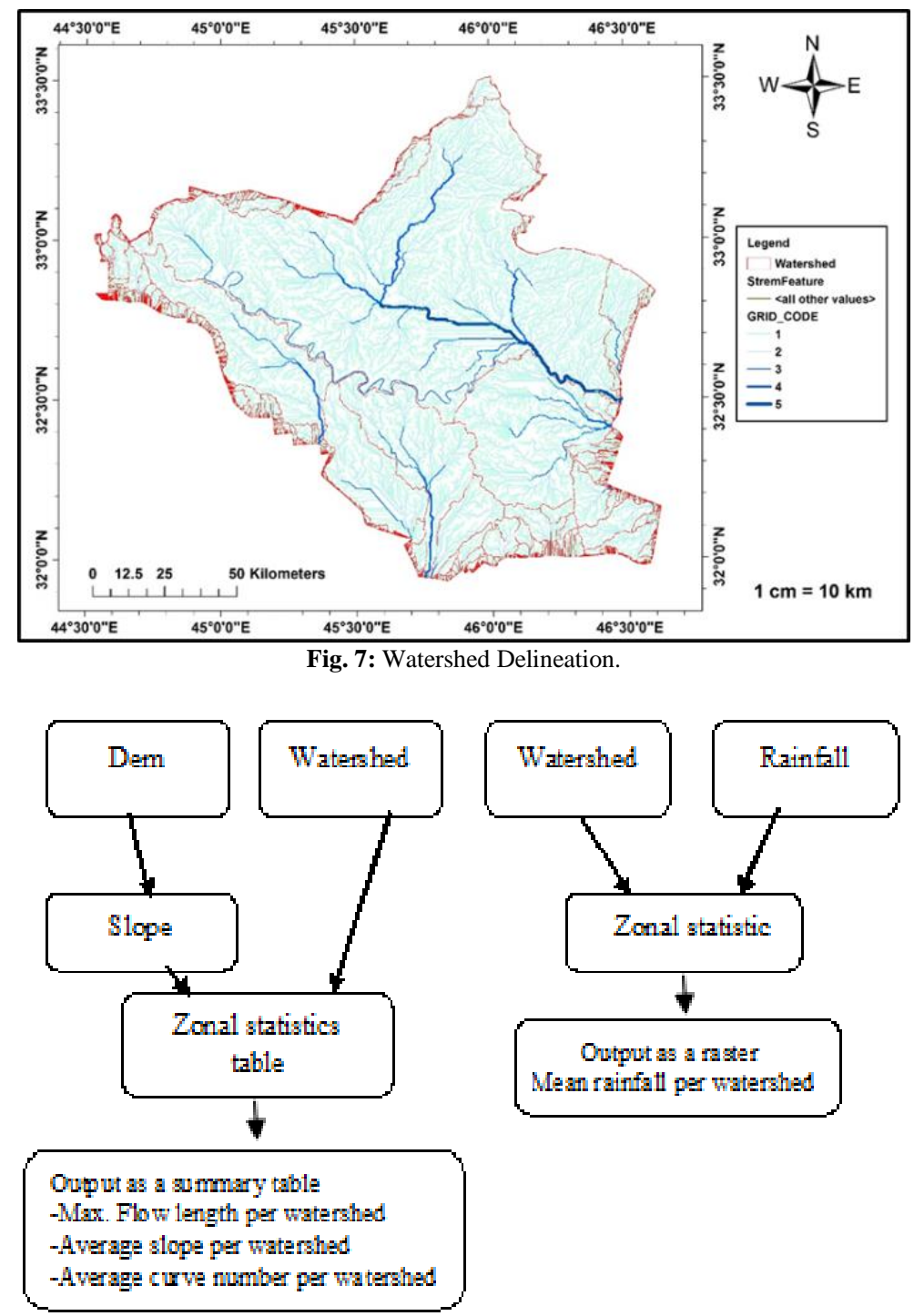

Fig. 8: Zonal Statistic Procedure in ArcGIS.

\section{Results and discussion}

In this study, TRMM rainfall daily data have been used to estimate the relationship between measured precipitation and DEM, in addition, to study the relationship between rainfall intensity and floodwaters areas.

Firstly, the accumulation data for the four rainstorm days analyzed using ArcGIS 10. The average accumulates precipitation derived. from TRMM throughout the investigated period (4-8 May 2013) (Figure 4). The minimum accumulated daily rainfall ranges from 3 $\mathrm{mm} /$ day to $16 \mathrm{~mm} /$ day, in the west and south of the studied area, while the east and center of the studied area obtained the maximum accumulated daily rainfall ranges from $24 \mathrm{~mm} /$ day to 41 $\mathrm{mm} /$ day, the main reasons are tracking of cyclonic storms that associated with the wind belt and topographic location. Secondly, using Dem and the procedure described above (fig.6) the watershed curtsied was identified including basin and sub-basin. Finally, using zonal statistic's tools the maximum basin influence from the flood was identified (red color in Fig.9), figure 9 illustrates Mean Zonal statistic for rainfall per watershed. In addition, Zonal statitic used to summarize the watershed characteristics, by the slope raster zones and the watershed, the output table that included max. Flow length per watershed, Average slope per watershed and Average curve number per watershed. Table 2 summarizes the rainfall attributes assigned to each watershed that can be directly employed during the regionalization procedure to form regions of homogeneous flood response.

The NDWI employed to identify the flood area. The results showed an intense increasing trend in the surface water after the flood. The study demonstrated the high performance of the proposed approach in simultaneously detecting the surface. In conclusion, NDWI has been proven effective in detecting the water surface changes. Figure 10-11 shows NDWI before/after the flood area in Wasit city/Eastern Iraq when a flood occurs due to heavy rainfall in May 2013. That flood brought serious damage the city. Figure 9 shows the estimated rainfall per watershed by GIS, which shows the region quite clearly. The estimated flood area is consistent with past flood area. 


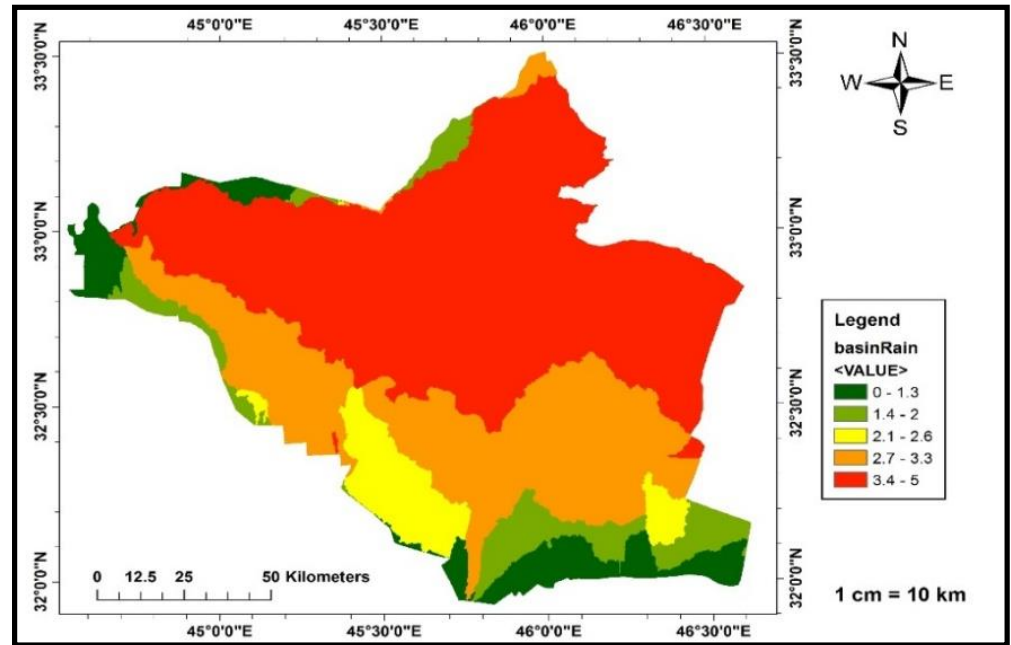

Fig. 9: Mean Zonal Statistic for Rainfall per Watershed.

Table 2: Zonal Statistic Table Slop per Watershed.

\begin{tabular}{|c|c|c|c|c|c|c|c|c|c|c|c|c|c|}
\hline Objecte & Value & Count & Area & Min & Max & Range & Mean & Std & Sum & Variety & Majority & Minority & Median \\
\hline 1 & 1 & 1797897 & 1.1080 & 1 & 6518 & 6517 & 1883.444 & 1872.167 & 3386238097 & 6173 & 20 & 10 & 2113 \\
\hline 2 & 2 & 896599 & 0.5525 & 1 & 6516 & 6515 & 1395.302 & 1743.194 & 1251026463 & 3286 & 20 & 3 & 20 \\
\hline 3 & 3 & 42979 & 0.0264 & 1 & 5026 & 5025 & 258.3682 & 722.951 & 11104406 & 232 & 20 & 2 & 20 \\
\hline 4 & 4 & 13481 & 0.0083 & 1 & 3311 & 3310 & 55.36466 & 199.7427 & 746371 & 46 & 20 & 5 & 20 \\
\hline 5 & 5 & 8771 & 0.0054 & 1 & 1599 & 1598 & 57.3515 & 173.1963 & 503030 & 21 & 20 & 2 & 20 \\
\hline 6 & 6 & 5508 & 0.0034 & 1 & 1584 & 1583 & 59.07171 & 146.6915 & 325367 & 10 & 20 & 137 & 20 \\
\hline 7 & 7 & 3251 & 0.0020 & 1 & 315 & 314 & 56.21009 & 91.47833 & 182739 & 8 & 20 & 315 & 20 \\
\hline 8 & 8 & 1817 & 0.0011 & 1 & 315 & 314 & 48.95102 & 83.52697 & 88944 & 8 & 20 & 315 & 20 \\
\hline 9 & 9 & 831 & 0.0005 & 1 & 289 & 288 & 63.38388 & 96.27587 & 52672 & 5 & 20 & 289 & 20 \\
\hline
\end{tabular}
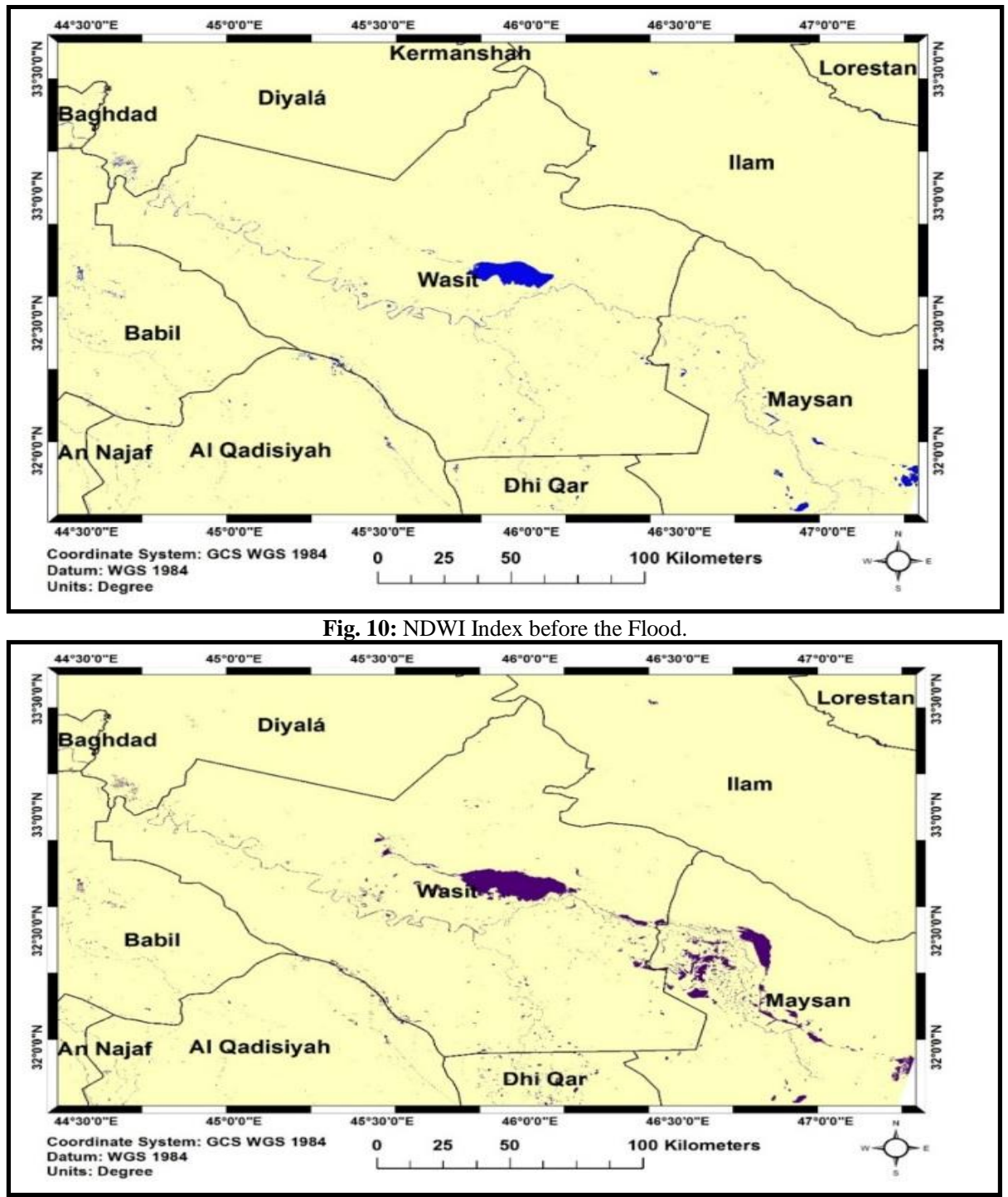

Fig. 11: NDWI Index after the Flood. 


\section{Conclusion and recommendations}

- The integration of remote-sensing data into GIS can be a powerful tool in planning, managing a research work and spatial data analysis to develop a decision-support system; to build and consulted for proper decisions about the disaster management and flood monitoring.

- $\quad$ TRMM estimates are a useful source of data, especially for the area with sparse gauge density.

- Study area suffers from long dry season and insufficiency of the water resources; So that it recommended using the water harvesting technique that would provide an opportunity to build dams to store water in drought areas.

- In the case study, medium resolution DEM data $(30 \mathrm{~m})$ has been employed. In future studies, however, it is recommended to employ high-resolution DEM data, as it tends to provide results that are more accurate. Application of highresolution DEM files is especially beneficial since mild channel slopes, and low relief characterized much of the region.

- This study characterization to prepare for regional flood frequency analysis; however, it can be extended to assign additional attributes to the watershed polygons, including soil type and land use indices, which have strong influences on regional flood response, in order to obtain enhanced results.

\section{References}

[1] Adler R F, Huffman G J, Bolvin D T, Curtis S, \& Nelkin E J (2000), Tropical Rainfall Distributions Determined Using TRMM Combined with Other Satellite and Rain Gauge Information, Journal of Applied Meteorology and Climatology, Vol. 39, pp. 2007-2023. https://doi.org/10.1175/15200450(2001)040<2007:TRDDUT>2.0.CO;2

[2] Chiu L S, Lim C \& Teng W (2004), Development of Agricultural Information System (AIS): Comparison of TRMM and Climate Division Rain Rates over Oklahoma. Presented at Second TRMM Int'l. Science Conf. Nara, Japan.

[3] Gu S, Gao H, Zhu Y, Zhao B, Lu N \& Zhang (2002), Remote sensing land surface wetness by use of TRMM/TMI microwave data, Meteorology and Atmospheric Physics, Vol. 80, pp.59-63. https://doi.org/10.1007/s007030200014.

[4] Harris A, Rahman S, Hossain F, Yarborough L, Bagtzoglou A, \& Easson G (2007), Satellite-based Flood Modeling Using TRMMbased Rainfall Products, Sensors, Vol.7, No. 12, pp. 3416-3427. https://doi.org/10.3390/s7123416.

[5] Huffman GJ, Adler R F, Bolvin D T, Gu G, Nelkin E J, Bowman K P, Hong Y, Stocker E F \& Wolff D B. (2007), The TRMM MultiSatellite Precipitation Analysis (TMPA): Quasi-Global, MultiYear, Combined-Sensor Precipitation Estimates at Fine Scale, Journal of Hydrometeorology, Vol. 8, pp.38-55. https://doi.org/10.1175/JHM560.1.

[6] Kummerow C, Barnes W, Kozu T, Shiue J \& Simpson J (1998) The Tropical Rainfall Measuring Mission (TRMM) sensor package, Journal of Atmospheric and Oceanic Technology, Vol. 15, pp. 809817. 0426(1998)015<0809:TTRMMT>2.0.CO;2.

[7] Liu Z, Chiu L, Teng W, Rui H, \& Serafino G (2002), TRMM Rainfall Products and Tools for Tropical Infectious Disease Studies. 15th Conference on Biometerology/Aerobiology. Kansas City, MO.

[8] Minghu C, Huizhong H, Dongyan M, Yanjun Q, Zhehu C \& Fengxian Z (2001), Study of 1998 heavy rainfall over the Yangtze River Basin using TRMM data, Advances in Atmospheric Sciences, Vol. 18, No.3, pp. 387-396. https://doi.org/10.1007/BF02919317.

[9] NASA (2010) TRMM Online Visualization and Analysis System (TOVAS). Retrieved 04 01, 2010, from National Aeronautics and Space Administration: http://gdata1.sci.gsfc.nasa.gov/daacbin/G3/gui.cgi?instance_id=TRMM_Monthly.

[10] Nicholson S E, Some B, McColumn J, Nelkin E, Klotter D, Berte Y, Diallo B M, Gaye I, Kpabeba G, Ndiaye O, Noukpozounkou J N, Tanu M M, Thiam A, Toure A A \& Traore A K (2003), Validation of TRMM and Other Rainfall Estimates with a High-Density Gauge Dataset for West Africa. Part I: Validation of GPCC Rainfall Prod- uct and Pre-TRMM Satellite and Blended Products, Journal of Applied Meteorology, Vol. 42, pp.1337-1354. https://doi.org/10.1175/15200450(2003)042<1337:VOTAOR >2.0.CO;2.

[11] Wang H, Ren L, \& Yang X (2009), Prospect for TRMM in rainfall estimates: a case study in the Laohahe basin, China. New Approaches to Hydrological Prediction in Data Sparce Regions, Hyderabad, India: IAHS Publ, Vol.33, pp. 253-258. 